\title{
Effect of coumarin concentration on the physical properties of $\mathrm{CdO}$ nanostructures
}

\author{
B. Sahin ${ }^{\mathrm{a}, *}$, F. Bayansal ${ }^{\mathrm{a}}$, M. Yuksel ${ }^{\mathrm{c}}$, N. Biyikli ${ }^{\mathrm{b}}$, H.A. Çetinkara ${ }^{\mathrm{a}}$ \\ ${ }^{a}$ Department of Physics, Faculty of Arts and Sciences, Mustafa Kemal University, Hatay, Turkey \\ ${ }^{\mathrm{b}}$ UNAM-National Nanotechnology Research Center, Bilkent University, Ankara, Turkey \\ ${ }^{\mathrm{c}}$ Vocational School of Health Sciences, Fatih University, Ankara, Turkey
}

Received 9 September 2013; received in revised form 10 October 2013; accepted 21 October 2013

Available online 6 November 2013

\begin{abstract}
In this work, nanostructured $\mathrm{CdO}$ films with different coumarin contents in the growth solution were fabricated on glass substrates by the SILAR method. The effects of coumarin content in the bath on optical, structural and morphological properties were studied by means of (UV-vis) spectrophotometer, SEM and XRD analysis. The analysis showed that the band gaps, surface morphologies and XRD peak intensities of the CdO films were found to change with coumarin content. A change in the band gap energy can be attributed to the improvement in crystallinity of the samples. XRD analysis showed that, the films have poly-crystalline structures with decent crystallinity levels.

(c) 2013 Elsevier Ltd and Techna Group S.r.l. All rights reserved.
\end{abstract}

Keywords: CdO; Nanostructured films; Band gap; SILAR; Coumarin effect

\section{Introduction}

Transparent conductive oxide (TCO) films have been extensively studied because of their use in semiconductor device technology [1-3]. Particularly, II-VI compound semiconductor oxide materials have attracted significant attention due to their potential applications in optoelectronics, ultraviolets light emitting devices, laser diodes, solar cells and optical communications $[4,5]$. However, among these compounds, cadmium oxide $(\mathrm{CdO})$ films received less attention mainly due to their narrow band gap energies compared to other wide band gap oxides [6-8]. CdO exhibits high electrical conductivity and carrier concentration because of its inherent nonstoichiometry. $\mathrm{CdO}$ has also been used as heat mirrors due to high reflectance in the infrared region, together with a relatively high transparency in the visible region. The unique combination of high electrical conductivity, high carrier concentration and high transparency in the visible range of the electromagnetic spectrum has prompted its applications in

\footnotetext{
*Corresponding author. Tel.: +90 326 2455845; fax: +90 3262455867 .

E-mail address: sahin38@gmail.com (B. Sahin).
}

solar cells [9]. The intensity of optical and electrical effects of $\mathrm{CdO}$ films depends on the deviations from the ideal $\mathrm{CdO}$ stoichiometry, as well as on the size and shape of the particles [10].

In general, additives are used in aqueous solution growth methods to control the surface morphology, the crystalline structure and to refine the grain size. The presence of additives also influences physical and mechanical properties of deposits such as grain size, brightness, internal stress, pitting, corrosion behavior and even chemical composition [11]. As an organic additive material, largely used in nickel plating industry, coumarin considerably refines the grain and makes the grains more uniform. Coumarins are attractive molecules due to their extended spectral range, high emission quantum yields and photostability [12]. Furthermore coumarin derivatives are frequently encountered as receptors and signaling units in sensors and biosensors as well as in advanced photophysical systems [13]. Coumarins exhibit fascinating and unique photophysical and spectroscopic properties; different derivatives can show different or even opposite behavior upon the same change in conditions. They show different absorption and fluorescence properties. Hence, they are interesting candidates not only from 

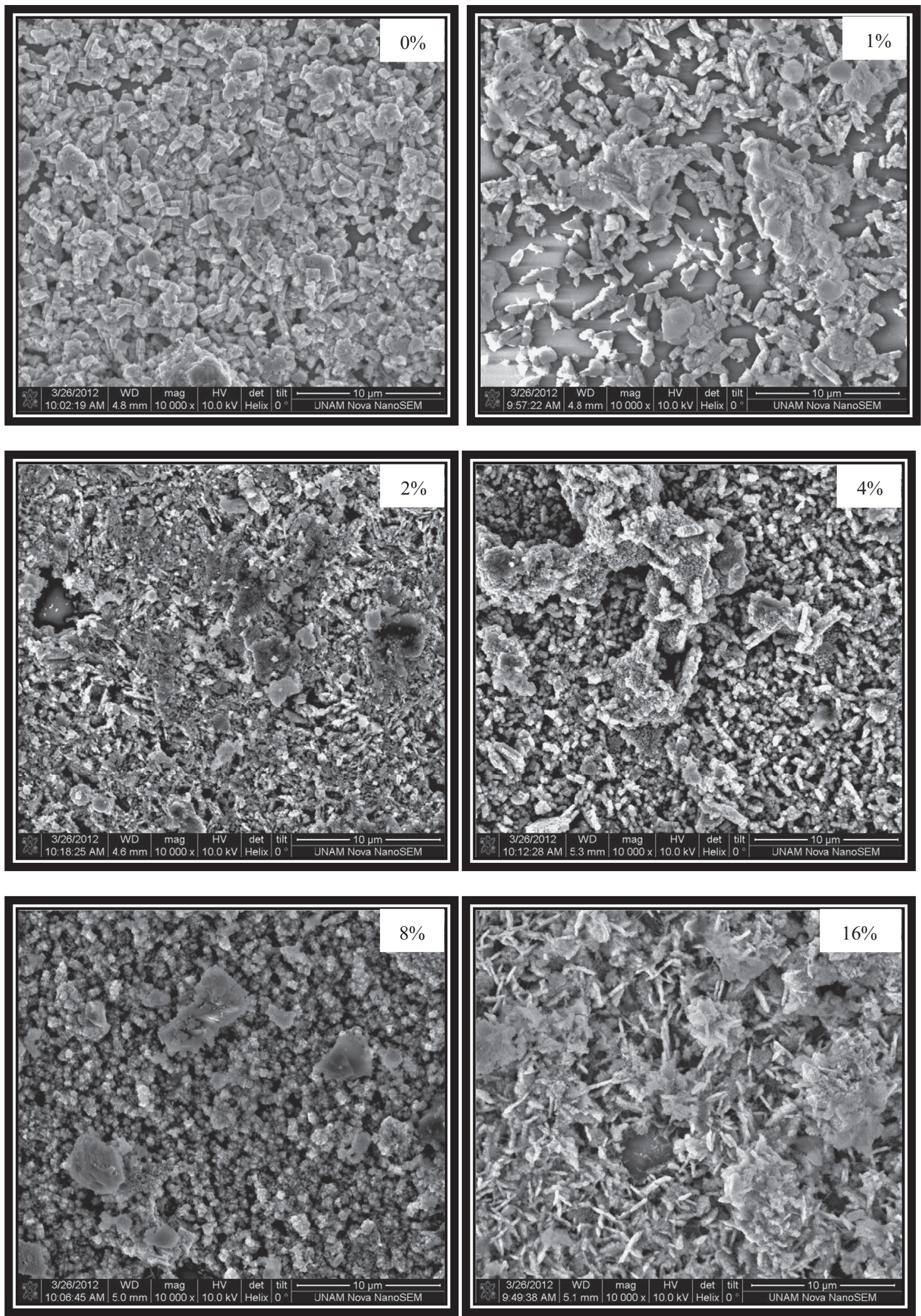

Fig. 1. SEM images of $\mathrm{CdO}$ films which were growth in pure and coumarin added (coumarin content: $1 \%, 2 \%, 4 \%, 8 \%$ and $16 \%$ ) baths.

the view of applications, but also with respect to an understanding of absorption and emission mechanisms [14].

Additives are generally added to the synthesis baths which are the main parts of the chemical-based growth techniques like electrochemical deposition (ECD), chemical bath deposition $(\mathrm{CBD})$, successive ionic layer adsorption and reaction (SILAR) etc. Among them SILAR is a relatively new liquidphase chemical deposition method. As compared to other 
liquid-phase synthesis methods, SILAR has various advantages including well suitability, good reproducibility, layer-bylayer growth feature and separation of the precursors for anionic and cationic solutions. This method is capable of producing metal oxide films $(\mathrm{CdO}, \mathrm{ZnO}, \mathrm{CuO}$ etc.) at relatively low temperatures and is widely used to deposit metal chalcogenides ( $\mathrm{CdS}, \mathrm{ZnS}, \mathrm{CdSe}$ etc.) multilayer and epitaxial films $[15,16]$.

As-grown films that are synthesized at low temperatures might contain high number of defects. Annealing of these films reduces the defect density and removes the possible hydroxide phases [6]. Accordingly, to obtain $\mathrm{CdO}$ films without traces of hydroxide and oxide vacancies, certain thermal annealing recipes are applied for example they are annealed at $450{ }^{\circ} \mathrm{C}$ for $1 \mathrm{~h}$ in oxygen atmosphere.

Literature survey reveals that there is no report on the effect of coumarin content on the properties of $\mathrm{CdO}$ films growth by the SILAR method or any other methods. In the present work, preparation and characterization of $\mathrm{CdO}$ films growth by the SILAR method is studied and the effect of coumarin content on the structural, morphological and optical film properties have been discussed.

\section{Experimental details}

All the chemical reagents used in the experiments were analytical grade, purchased from Sigma-Aldrich Company and Merck KGaA. Cleaning process of the substrates (microscope glass slides) consisted of three steps which were cleaning in dilute sulfuric acid solution $\left(\mathrm{H}_{2} \mathrm{SO}_{4}: \mathrm{H}_{2} \mathrm{O}, 1: 5\right.$ by volume), in acetone and in double distilled water for $5 \mathrm{~min}$ each in ultrasonic bath [17]. Synthesis of the films was described as follows: $2.66 \mathrm{~g}$ cadmium acetate was weighted and mixed with $100 \mathrm{ml}$ double distilled water $\left(18.2 \mathrm{M} \Omega \mathrm{cm}^{-2}\right)$ to obtain $0.1 \mathrm{M}$ cadmium acetate solution. Then the solution was stirred in a magnetic stirrer at the room temperature for $1 \mathrm{~h}$ in order to get a transparent and well-dissolved solution. After stirring, the $\mathrm{pH}$ value of the solution was increased to $\approx 12.0$ by adding ammonium hydroxide $\left(\mathrm{NH}_{4} \mathrm{OH}\right)$. The solution was heated up to $85^{\circ} \mathrm{C}$. The substrates were dipped into the solution and kept for $30 \mathrm{~s}$. Then they were dipped into hot water $\left(85^{\circ} \mathrm{C}\right)$ for another $30 \mathrm{~s}$. This cycle was applied for 30 times. To investigate the effects of coumarin content to the films, six series of samples were produced. Coumarins are a very large group of 1,2-benzopyrones derivatives that are largely distributed in a variety of natural plant sources [18]. We added coumarin $4\left(\mathrm{C}_{10} \mathrm{H}_{8} \mathrm{O}_{3}\right)$ organic dye. Coumarin 4 was chosen as a organic dye because of its high fluorescence efficiency, chemical and photo stability $[19,20]$.

As a result, we have obtained $\mathrm{Cd}(\mathrm{OH})_{2}$ nanostructured films. The first bath was pure (i.e. contains only cadmium acetate, water and ammonium hydroxide). The other baths contained 1\%,2\%, 4\%,8\%, 16\% coumarin, respectively. Then $\mathrm{Cd}(\mathrm{OH})_{2}$ films were annealed at $450{ }^{\circ} \mathrm{C}$ for $1 \mathrm{~h}$ in a PROTHERM PTF 12/50/450 tube furnace in a controlled oxygen ambient in order to convert $\mathrm{Cd}(\mathrm{OH})_{2}$ into $\mathrm{CdO}$.

\section{Results and discussion}

\subsection{Morphological analysis}

The morphology and microstructure of the $\mathrm{CdO}$ samples were examined by scanning electron microscopy (SEM). Fig. 1 shows $\mathrm{CdO}$ nanoparticles growth in pure and coumarin added (coumarin content: $1 \%, 2 \%, 4 \%, 8 \%$ and $16 \%$ ) baths on glass substrates. It can be seen that all the substrates are fully covered by $\mathrm{CdO}$ nanoparticles. The distribution of grains is heterogeneous and their diameters range from 26 to $19 \mathrm{~nm}$. It is observed that the pure $\mathrm{CdO}$ films are the most homogeneous one with the uniform grain size. The surface morphology and grain size of $\mathrm{CdO}$ films were changed considerably as a function of coumarin content that is in agreement with the studies by Mouanga et al. [21]. This organic molecule of high molecular weight is adsorbed preferentially on active sites precisely those of cadmium. It equalizes growth speeds in the crystals and contributes to a finer alloy and more regular structure. Fig. 2 shows the cross-sectional image of $\mathrm{CdO}$ films. Thicknesses of films were found to change from 2.20 to $2.90 \mu \mathrm{m}$ with the increase of Coumarin concentration.

\subsection{Structural analysis}

XRD analyses were employed to study the crystal structures of the CdO films. Fig. 2 shows the typical XRD patterns of the films that have different coumarin concentrations in the growth solution. All diffraction peaks can be clearly indexed to cubic CdO phases (JCPDS Card no.: 05-0640 for CdO). Fig. 3(a) shows the pure and $1 \%, 2 \%$, coumarin content and it exhibits decent crystallinity. But the intensities of (111) and (200) peaks in the $4 \%, 8 \%, 16 \%$ samples were found to be slightly

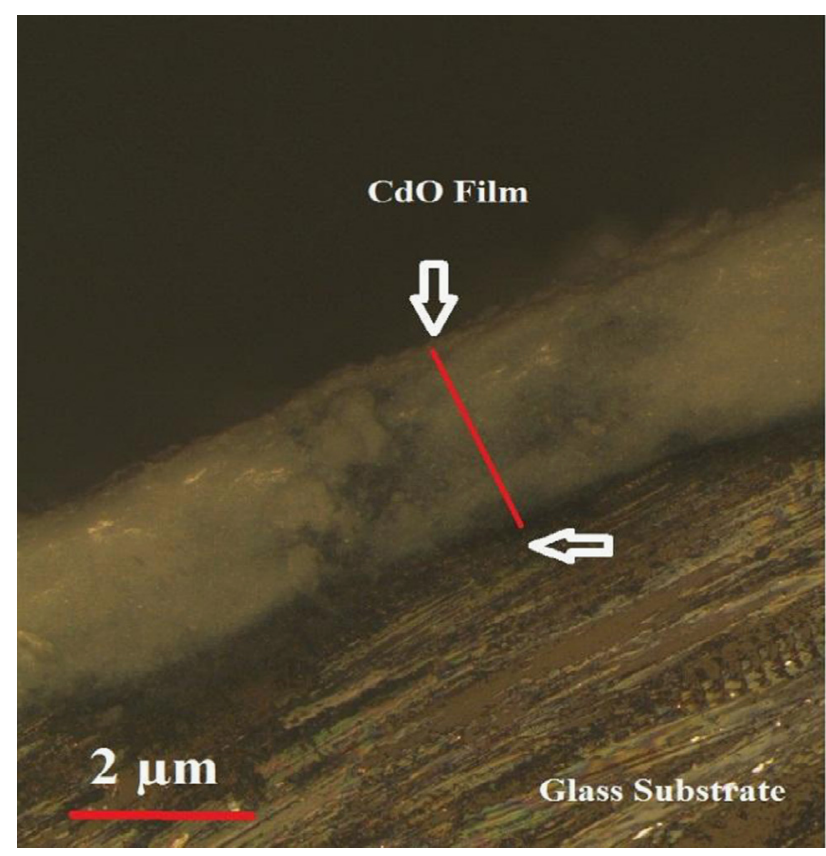

Fig. 2. Crossectional image of the $\mathrm{CdO}$ film. 
a

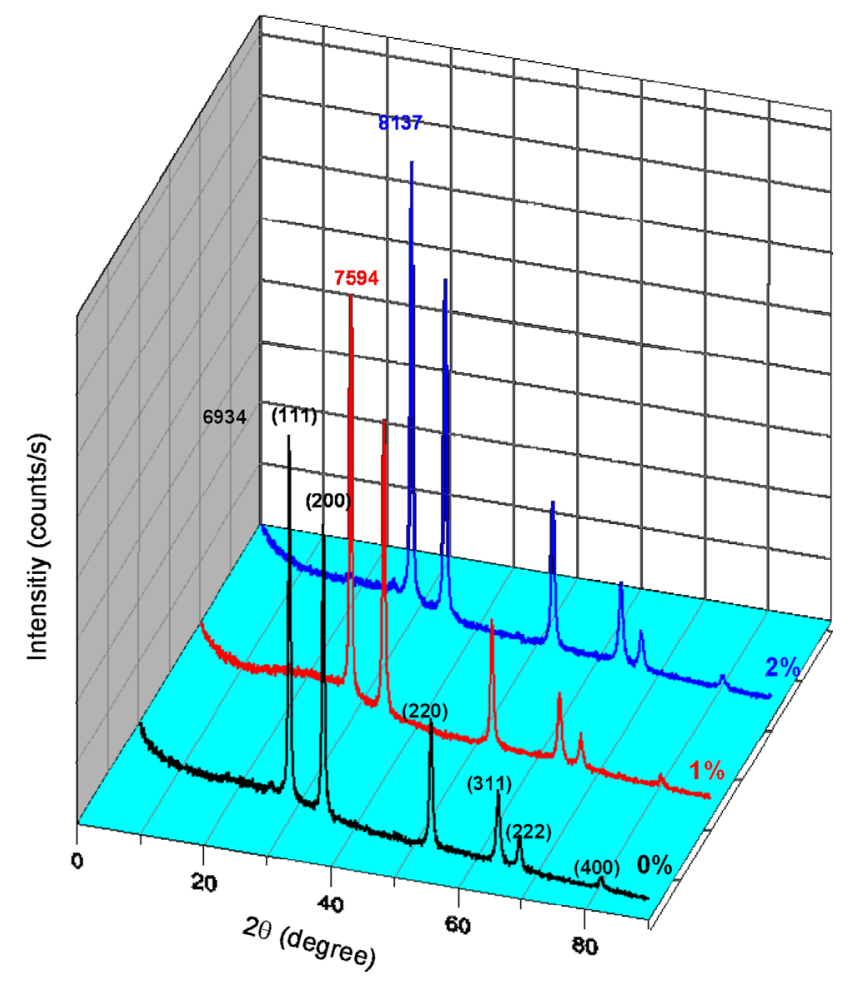

b

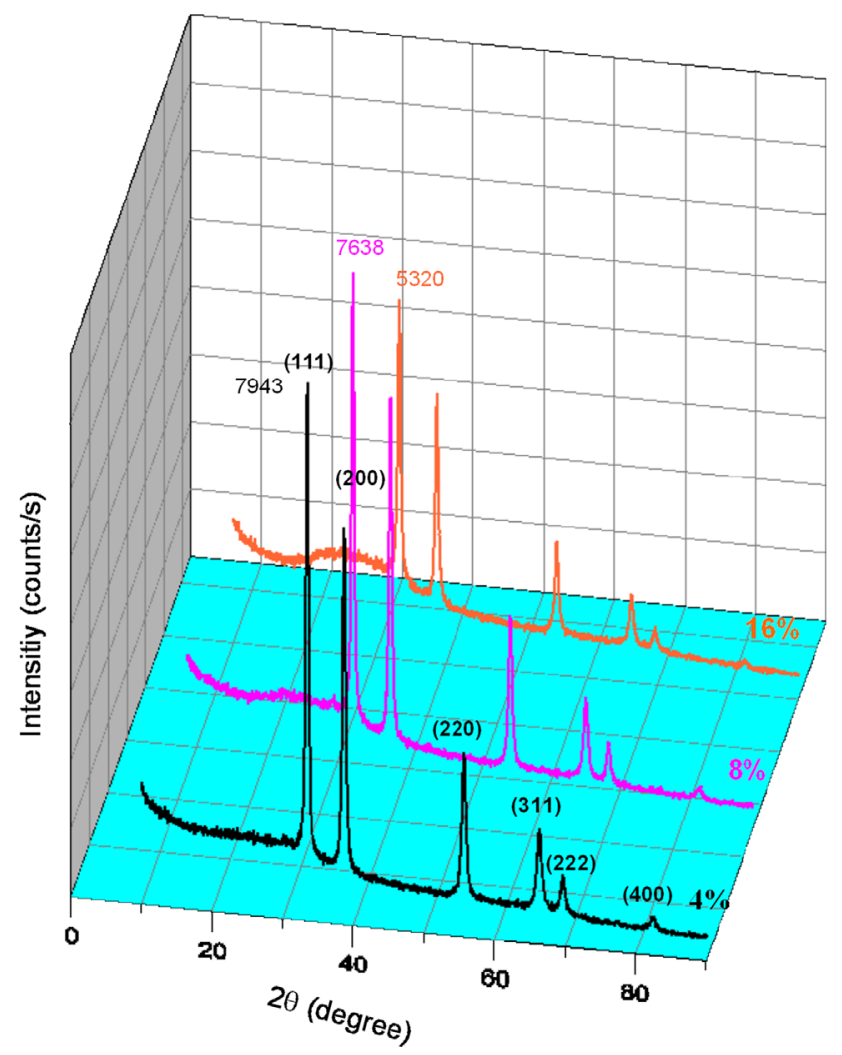

Fig. 3. XRD patterns of the films. (a) pure, $1 \%, 2 \%$ and (b) $4 \%, 8 \%, 16 \%$ coumarin content.

decreased as seen in Fig. 3(b). The reason for this may be, up to $2 \%$ content, coumarin ions replace the oxygen ions in the $\mathrm{CdO}$ lattice. However, at higher coumarin percentages, apart from replacing the oxygen ions, coumarin ions might occupy the interstitial positions in the $\mathrm{CdO}$ lattice. When the coumarin content in the bath further increases, the intensities of the (111) and (200) peak decrease evidently. Therefore, it can be concluded that the film formation mechanism and hence the crystallinity change with coumarin concentration [22].

The average grain sizes $(D)$ of the $\mathrm{CdO}$ structures was calculated from the full-width at the half maximum $(\beta)$ of a peak, using the Debye-Scherrer's equation [23]

$D=\frac{0.90 \lambda}{\beta \cos \theta}$

where $\lambda$ is the wavelength of $\mathrm{X}$-ray radiation and $\theta$ is the Bragg's angle of the corresponding peak. Each X-ray diffraction peak obtained in a diffractometer is broadened due to instrumental and physical factors (grain size and lattice strains). The calculated average grain sizes of the structures are given in Table 1. As seen from the table grain sizes of the structures were increased with coumarin content up to $2 \%$, and decreased for higher coumarin concentrations. This result is in good agreement with the SEM measurements. The measured grain size values are plotted as a function of coumarin concentration in Fig. 4. The dislocation density $(\delta)$ defined as the length of dislocation lines per unit volume of the crystal can be estimated from the following relation using the simple approach of Williamson and Smallman [24].

$\delta=\frac{1}{D^{2}}$

Table 1

Band gap and structural parameters of $\mathrm{CdO}$ films.

\begin{tabular}{llll}
\hline $\begin{array}{l}\text { Coumarin content in the } \\
\text { growth solution \% }\end{array}$ & $\begin{array}{l}\mathbf{E}_{\mathbf{g}} \\
(\mathbf{e V})\end{array}$ & $\begin{array}{l}\text { Average grain } \\
\text { size }(\mathbf{D})(\mathbf{n m})\end{array}$ & $\begin{array}{l}\text { Dislocation density } \\
\mathbf{x ~ 1 0} \mathbf{1 0}^{\mathbf{1 5}} / \mathbf{~ m}^{\mathbf{2}}\end{array}$ \\
\hline 0 & 1.86 & 26.0 & 1.47 \\
1 & 1.89 & 27.0 & 1.37 \\
2 & 1.90 & 28.8 & 1.20 \\
4 & 1.92 & 27.2 & 1.35 \\
8 & 1.96 & 26.5 & 1.42 \\
16 & 2.06 & 19.0 & 2.77 \\
\hline
\end{tabular}

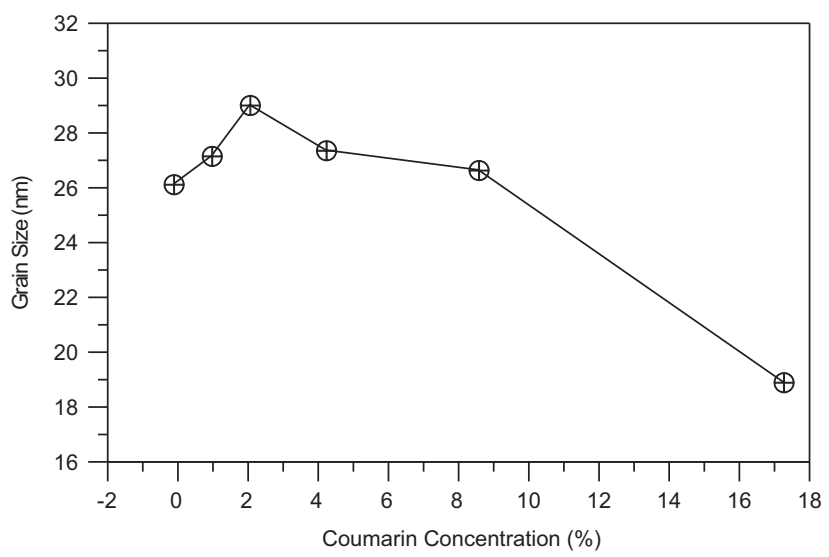

Fig. 4. Effect of coumarin concentration on the grain size. 
where $D$ is average grain size of crystal. Dislocations play an important role in surface properties. Both morphological and optical properties of thin films depend strongly defect concentration. Moreover, controlling and minimizing the density of defects or dislocations becomes also important to realize useful devices based on transparent conducting oxides (TCOs) and transparent oxide semiconductors (TOSs). Therefore, understanding the interactions between dislocations and structural properties is a significant scientific interest and has an practical importance in materials design [25,26]. Dislocation density values of the $\mathrm{CdO}$ nanostructures depending on coumarin content are listed in Table 1.

\subsection{Optical analysis}

Optical absorption spectra of the films in spectral range of $190-1100 \mathrm{~nm}$ was determined by using UV-visible spectrophotometer (Thermo Scientific Genesys $10 \mathrm{~S}$ UV-vis). The analysis of the dependence of absorption coefficient on photon energy in the high absorption regions is performed to obtain the detailed information about the energy band gaps of the films. The optical band gap energy values of the films were determined by using the following relation [27].

$(\alpha h \nu)=C\left(h \nu-E_{g}\right)^{m}$

where $C$ is an energy-independent constant, $E_{g}$ is the optical band gap and $m$ is an index that characterizes the optical absorption process which is theoretically equal to 2 and $1 / 2$ for indirect and direct allowed transitions, respectively. According to the previous theoretical and experimental results $\mathrm{CdO}$ exhibit direct inter band transitions [28]. Thus $m$ can be chosen as $1 / 2$. The band gap value can be determined by extrapolating the straight line portion of $(\alpha h \nu)^{2}$ vs. $(h \nu)$ plot.

Fig. 5(a) illustrates the plots of $(\alpha h \nu)^{2}$ vs. $h \nu$ of $\mathrm{CdO}$ films. The $E_{g}$ values were found to be $1.86,1.89,1.90,1.92,1.96$ and $2.06 \mathrm{eV}$ for the films which are pure and $1 \%, 2 \%, 4 \%, 8 \%$, $16 \%$ coumarin contents, respectively. As a result, the optical band gap of the $\mathrm{CdO}$ film can be controlled by coumarin concentration. Optical band gap values of the samples indicate a regular trend depending on the coumarin rate. With various contents of coumarin, the band gap of $\mathrm{CdO}$ can be modulated with coumarin concentration during the film growth stage. As summarized in Table 1, the shift in the optical band gap of the $\mathrm{CdO}$ films can be explained by the coumarin rate and grain size [29]. It was found that the particle sizes changes with coumarin rate. With the increase in coumarin rate from $0 \%$ to $16 \%$, the optical absorption edge shifted towards longer wavelengths $(1.86-2.06 \mathrm{eV})$ which might be attributed to change in grain size $[30,31]$. The effect of coumarin ratio on the optical band gap is shown in Fig. 5(b).

The transmittance spectra as a function of coumarin concentration recorded in the wavelength range of $200-1200 \mathrm{~nm}$ are shown in Fig. 6. The pure $\mathrm{CdO}$ film has the highest transmittance (11\%) at longer wavelengths. The transmittance decreased rapidly with increasing coumarin concentration. As the coumarin concentration reaches 8 at $\%$ and beyond, the transmittance decreases under $3 \%$. This result is usually a
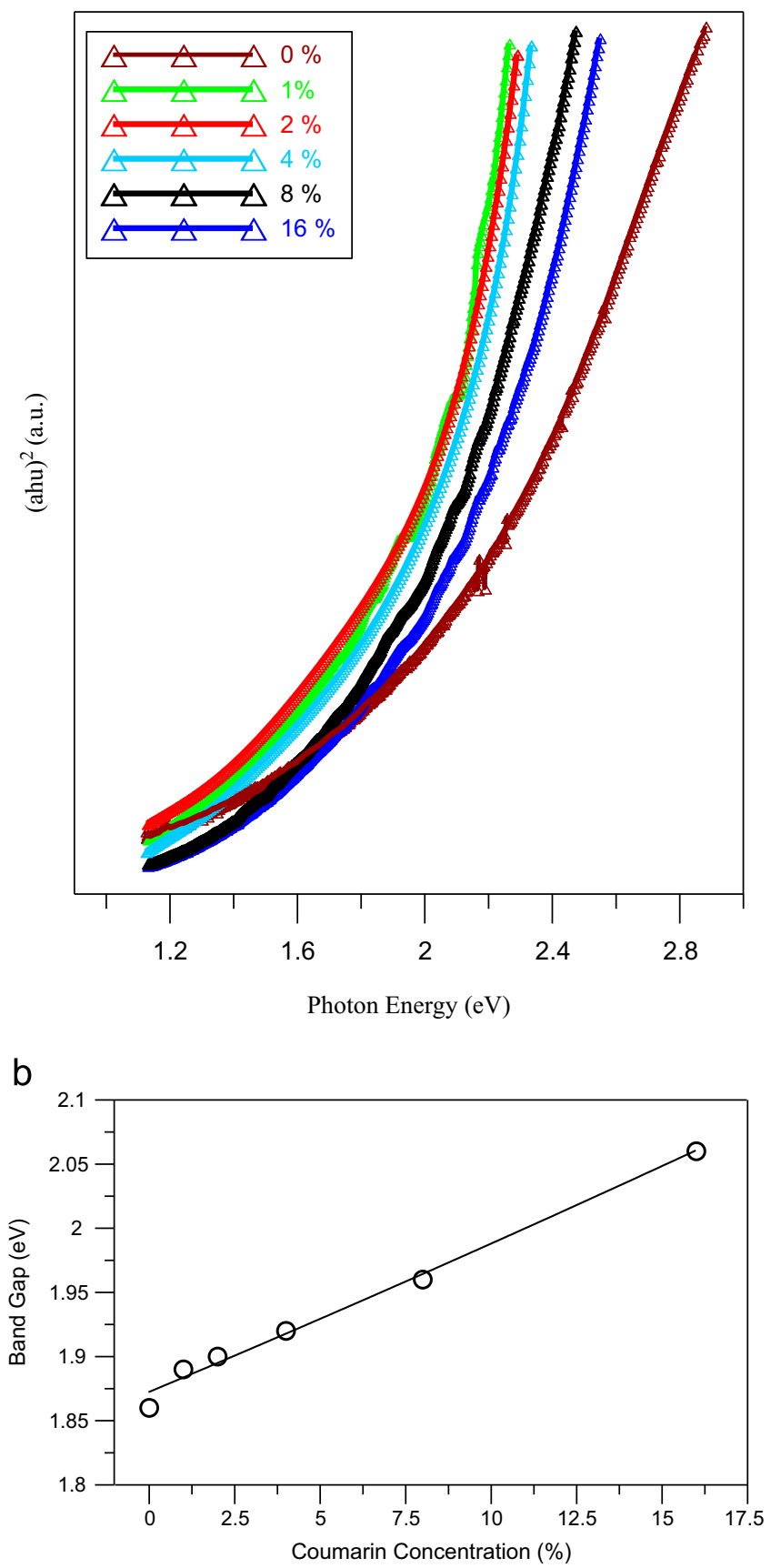

Fig. 5. (a) $(\alpha h v)^{2}$ vs. photon energy plots of the films: pure, $1 \%, 2 \%, 4 \%, 8 \%$ and $16 \%$ coumarin content (b) effect of coumarin concentrations on the optical band gap.

attributed by a partial coverage of the substrate by additives which block the active sites, change the nucleation rate and as a result change the film structure $[11,21]$. These findings are in good agreement with our previous results on coumarin added $\mathrm{CuO}$ nanostructures [32], in which coumarin content did affected the transmittance with descending direction. As a result, film properties changes with increase in the coumarin content. We can say that film properties are a key factor which enhances the structural and optical characteristics in optoelectronic materials. 


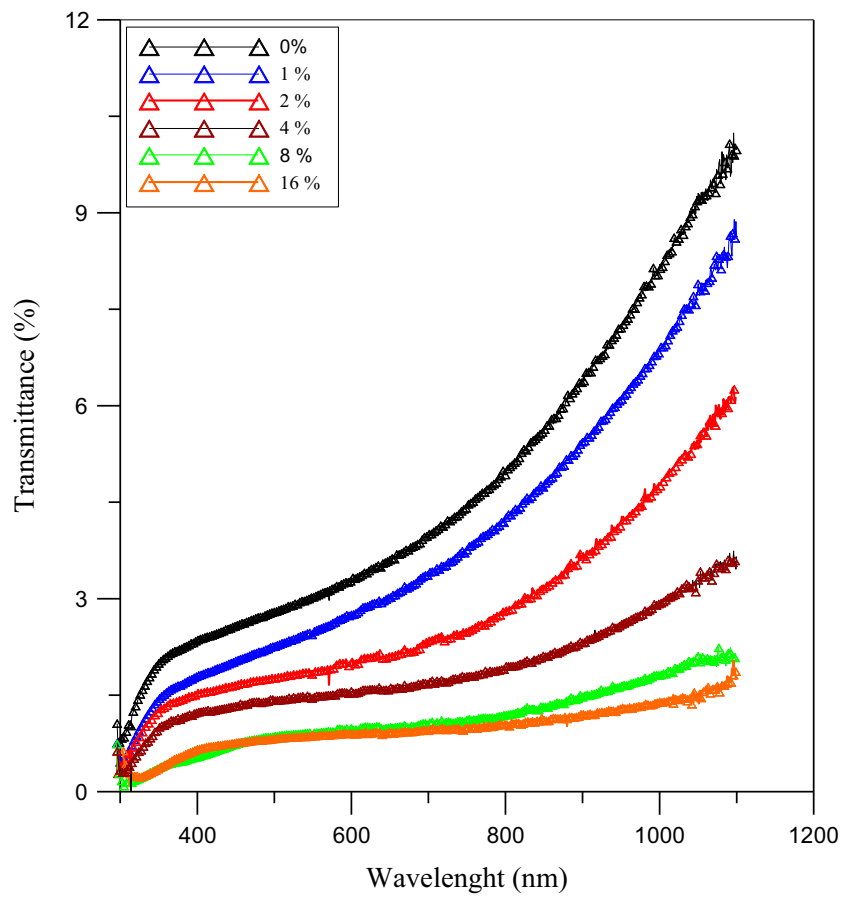

Fig. 6. Transmittance spectra of $\mathrm{CdO}$ films as a function of coumarin concentration.

\section{Conclusion}

The influence of coumarin content to the structural, morphological and optical properties of $\mathrm{CdO}$ films synthesized by SILAR method have been investigated. The $\mathrm{CdO}$ films were found to be polycrystalline with cubic structure. Coumarin addition to the growth bath caused an initial increase (up to $2 \%)$ in the intensities of (111) and (200) peaks but eventually decrease for higher coumarin content levels (more than $4 \%$ ). It is observed from the SEM images and XRD patterns that the grain sizes of the structures were increased with coumarin content up to $2 \%$, which then also decreased for the higher levels. The optical band gaps of the pure and $1 \%, 2 \%, 4 \%, 8 \%$, $16 \%$ coumarin content $\mathrm{CdO}$ films were determined to be 1.86 , $1.89,1.90,1.92,1.96$ and $2.06 \mathrm{eV}$, respectively. Both optical band gap and morphological properties could be controlled and calibrated by adjusting the coumarin concentrations. This controlling mechanism might be instrumental for different optoelectronic device applications where tunable material properties including band gap and crystalline quality are of critical importance. We believe that our proposed SILARbased nanostructured $\mathrm{CdO}$ film growth technique is promising for tunable optoelectronic materials synthesis.

\section{References}

[1] M. Yan, M. Lane, C.R. Kannewurf, R.P.H. Chang, Highly conductive epitaxial CdO thin films prepared by pulsed laser deposition, Appl. Phys. Lett. 78 (2001) 2342-2345.

[2] M.S. Tokumoto, A. Smith, C.V. Santilli, S.H. Pulcinelli, A.F. Craievich, E. Elkaim, A. Traverse, V. Briois, Structural electrical and optical properties of undoped and indium doped $\mathrm{ZnO}$ thin films prepared by the pyrosol process at different temperatures, Thin Solid Films 416 (2002) 284-293.
[3] K.L. Chopra, S.R. Das, Thin Film Solar Cells, Plenum Press, New York, 1983, p. 346 (Chapter 3).

[4] N. İto, Y. Sato PK Song, A Kaijio, K Inoue, Y. Shigesato, Electrical and optical properties of amorphous indium zinc oxide films, Thin Solid Films 496 (2006) 99-103.

[5] A.A. Dakhel, Optoelectronic properties of Eu- and H-codoped CdO films, Curr. Appl. Phys. 11 (2011) 11-15.

[6] R.R. Salunkhe, D.S. Dhawale, T.P. Gujar, C.D. Lokhande, Structural, electrical and optical studies of SILAR deposited cadmium oxide thin films: Annealing effect, Mater. Res. Bull. 44 (2009) 364-368.

[7] D.M.C. Galicia, R.C. Perez, O.J. Sandoval, S.J. Sandoval, G.T. Delgado, C.I.Z. Romero, High transmittance $\mathrm{CdO}$ thin films obtained by the solgel method, Thin Solid Films 317 (2000) 105-108.

[8] Z. Zhao, D.L. Morel, C.S. Ferekides, Electrical and optical properties of tin-doped $\mathrm{CdO}$ films deposited by atmospheric metalorganic chemical vapor deposition, Thin Solid Films 413 (2002) 203-211.

[9] S.M. Pawar, B.S. Pawar, J.H. Kim, Oh-Shim Joo, C.D. Lokhande, Recent status of chemical bath deposited metal chalcogenide and metal oxide thin films, Curr. Appl. Phys. 11 (2011) 117-161.

[10] C.C. Vidyasagar, Y. Arthoba Naik, T.G. Venkatesh, R. Viswanatha, Solidstate synthesis and effect of temperature on optical properties of $\mathrm{Cu}-\mathrm{ZnO}$, $\mathrm{Cu}-\mathrm{CdO}$ and $\mathrm{CuO}$ nanoparticles, Powder Technol. 214 (2011) 337-343.

[11] M. Mouanga, L. Ricq, G. Douglade, J. Douglade, P. Bercot, Influence of coumarin on zinc electrodeposition, Surf. Coat. Technol. 201 (2006) $762-767$.

[12] H.E. Katerinopoulos, The coumarin moiety as chromophore of fluorescent ion indicators in biological systems, Curr. Pharm. Des. 10 (2004) $3835-3852$.

[13] B.M. Wong, J.G. Cordaro, Coumarin dyes for dye-sensitized solar cells: a long-range-corrected density functional study, J. Chem. Phys. 129 (2008) 214703-214711.

[14] N.A. Nemkovich, H. Reisb, W. Baumannb, Ground and excited state dipole moments of coumarin laser dyes: Investigation by electro-optical absorption and emission methods, J. Lumin. 71 (1997) 255-263.

[15] X.D. Gao, X.M. Li, W.D. Yu, Synthesis and optical properties of $\mathrm{ZnO}$ nanocluster porous films deposited by modified SILAR method, Appl. Surf. Sci. 229 (2004) 275-281.

[16] K.C. Preetha, K.V. Murali, A.J. Ragina, K. Deepa, T.L. Remadevi, Effect of cationic precursor $\mathrm{pH}$ on optical and transport properties of SILAR deposited nano crystalline PbS thin films, Curr. Appl. Phys. 12 (2012) 53-59.

[17] F Bayansal, S Kahraman, G Çankaya, H.A Çetinkara, H.S. Güder, H. M. Çakmak, Growth of homogenous $\mathrm{CuO}$ nano-structured thin films by a simple solution method, J. Alloys Compd. 509 (2011) 2094-2098.

[18] F. Borges, F. Roleira, N. Milhazes, L. Santana, E. Uriarte, Simple coumarins and analogues in medicinal chemistry: occurrence, synthesis and biological activity, Curr. Med. Chem. 12 (2005) 887-916.

[19] T. Suratwala, Z. Gardlund, K. Davidson, D.R Uhlmann, S. Bonilla, N. Peyghanmbarian, Photostability of silylated coumarin dyes in polyceram hosts, J. Sol-Gel Sci. Technol. 8 (1/2/3) (1997) 973-978.

[20] T. Suratwala, Z. Gardlund, K. Davidson, D.R. Uhlmann, J. Watson, S. Bonilla, N. Peyghambarian, Silylated Coumarin Dyes in Sol-Gel Hosts. II. Photostability and Sol-Gel Processing, Chem. Mater. 10 (1998) 199-209.

[21] M. Mouanga, L. Ricq, P. Berçot, Electrodeposition and characterization of zinc-cobalt alloy from chloride bath; influence of coumarin as additive, Surf. Coat. Technol. 202 (2008) 1645-1651.

[22] R.J. Deokate, S.M. Pawar, A.V. Moholkar, V.S. Sawant, C.A. Pawar, C. H. Bhosale, K.Y. Rajpure, Spray deposition of highly transparent fluorine doped cadmium oxide thin films, Appl. Surf. Sci. 254 (2008) 2187-2195.

[23] A. Chandra Bose, P. Thangadurai, S. Ramasamy, Grain size dependent electrical studies on nanocrystalline $\mathrm{SnO}_{2}$, Mater. Chem. Phys. 95 (2006) 72-78.

[24] G.B. Williamson, R.C. Smallman, Dislocation densities in some annealed and cold-worked metals from measurements on the X-ray debye-scherrer spectrum, Philos. Mag. 1 (1956) 34-35.

[25] D. Balzar, H. Ledbetter, P.W. Stephens, E.T. Park, J.L. Routbort, Dislocation-density changes upon poling of polycrystalline $\mathrm{BaTiO}_{3}$, Phys. Rev. B 59 (1999) 3414-3420. 
[26] S. Ni, Y.B. Wang, X.Z. Liao, R.B. Figueiredo, H.Q. Li, S.P. Ringer, T. G. Langdon, Y.T. Zhu, The effect of dislocation density on the interactions between dislocations and twin boundaries in nanocrystalline materials, Acta. Mater. 60 (2012) 3181-3189.

[27] H.M. Cakmak, H.A. Cetinkara, S. Kahraman, F. Bayansal, M. Tepe, H. S. Guder, M.A. Cipiloglu, Effects of thermal oxidation temperature on vacuum evaporated tin dioxide film, Superlattices Microstructures 51 (2012) 421-429.

[28] S Aksoy, Y. Caglar, S. Ilican, M. Cağlar, Effect of heat treatment on physical properties of $\mathrm{CdO}$ films deposited by sol-gel method, Int. J. Hydrogen. Energy 34 (2009) 5191-5195.

[29] F. Yakuphanoglu, Synthesis and electro-optic properties of nanosizedboron doped cadmium oxide thin films for solar cell applications, Solar Energy 85 (2011) 2704-2709.
[30] V.R. Shinde, C.D. Lokhande, R.S. Mane, S.H. Han, Hydrophobic and textured $\mathrm{ZnO}$ films deposited by chemical bath deposition: annealing effect, Appl. Surf. Sci. 245 (2005) 407-413.

[31] Y. Zhang, W. Fa, F. Yang, Z. Zheng, P. Zhang, Electrochemical oxidation and reduction of the $\mathrm{La}_{0.2} \mathrm{Sr}_{0.8} \mathrm{CoO}_{3-\delta}$ phases: Control of itinerant ferromagnetism and magnetoresistance, Ionics 16 (2010) 815-820.

[32] F. Bayansal, B Sahin, M Yüksel, N Biyikli, H.A Çetinkara, H.S Güder, Influence of coumarin as an additive on $\mathrm{CuO}$ nanostructures prepared by successive ionic layer adsorption and reaction (SILAR) method, J. Alloys Compd. 566 (2013) 78-82. 